\title{
Phosphorylation of Gephyrin in Zebrafish Mauthner Cells Governs Glycine Receptor Clustering and Behavioral Desensitization to Sound
}

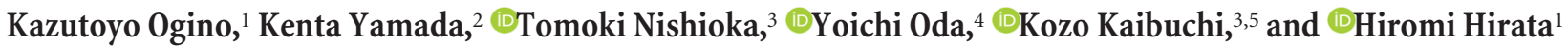 \\ ${ }^{1}$ Department of Chemistry and Biological Science, College of Science and Engineering, Aoyama Gakuin University, Sagamihara, 252-5258, Japan, ${ }^{2}$ Center for \\ Frontier Research, National Institute of Genetics, Mishima, 411-8540, Japan, ${ }^{3}$ Department of Cell Pharmacology, Graduate School of Medicine, Nagoya \\ University, Nagoya, 466-8550, Japan, ${ }^{4}$ Division of Biological Science, Graduate School of Science, Nagoya University, Nagoya, 464-8602, Japan, \\ and ${ }^{5}$ Institute for Comprehensive Medical Science, Fujita Health University, Toyoake, 472-1192, Japan
}

The process by which future behavioral responses are shaped by past experiences is one of the central questions in neuroscience. To gain insight into this process at the molecular and cellular levels, we have applied zebrafish larvae to explore behavioral desensitization to sound. A sudden loud noise often evokes a defensive response known as the acoustic startle response (ASR), which is triggered by firing Mauthner cells in teleosts and amphibians. The probability of evoking ASR by suprathreshold sound is reduced after exposure to repetitive auditory stimuli insufficient in amplitude to evoke the ASR (subthreshold). Although it has been suggested that the potentiation of inhibitory glycinergic inputs into Mauthner cell is involved in this desensitization of the ASR, the molecular basis for the potentiation of glycinergic transmission has been unclear. Through the in vivo monitoring of fluorescently-tagged glycine receptors (GlyRs), we here showed that behavioral desensitization to sound in zebrafish is governed by GlyR clustering in Mauthner cells. We further revealed that CaMKII-dependent phosphorylation of the scaffolding protein gephyrin at serine 325 promoted the synaptic accumulation of GlyR on Mauthner neurons through the enhancement of the gephyrin-GlyR binding, which was indispensable for and could induce desensitization of the ASR. Our study demonstrates an essential molecular and cellular basis of sound-induced receptor dynamics and thus of behavioral desensitization to sound.

Key words: glycinergic; Mauthner; synapse; zebrafish

Significance Statement

Behavioral desensitization in the acoustic startle response of fish is known to involve the potentiation of inhibitory glycinergic input to the Mauthner cell, which is a command neuron for the acoustic startle response. However, the molecular and cellular basis for this potentiation has been unknown. Here we show that an increase in glycine receptor (GlyR) clustering at synaptic sites on zebrafish Mauthner cells is indispensable for and could induce desensitization. Furthermore, we demonstrate that CaMKIImediated phosphorylation of the scaffolding protein gephyrin promotes GlyR clustering by increasing the binding between the $\beta$-loop of GlyRs and gephyrin. Thus, the phosphorylation of gephyrin is a key event which accounts for the potentiation of inhibitory glycinergic inputs observed during sound-evoked behavioral desensitization.

\section{Introduction}

Animals must continually integrate information from their environment to modify behavioral responses to both threatening and non-threating stimuli. For instance, a sudden loud noise often evokes a largely unconscious defensive response known as the acoustic startle response (ASR). However, if animals are repeatedly exposed to the same noise (conditioned), and experience no 


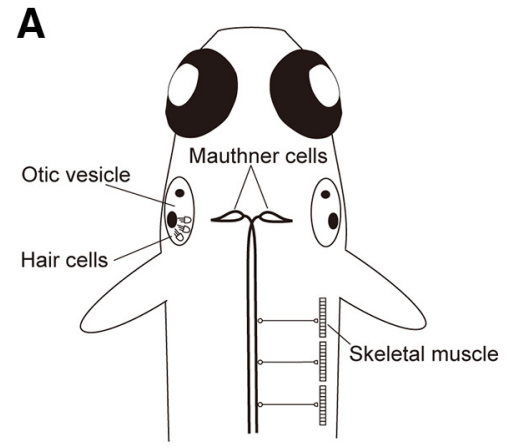

B

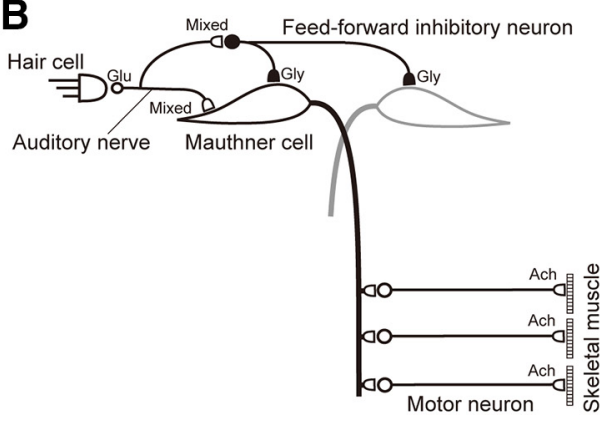

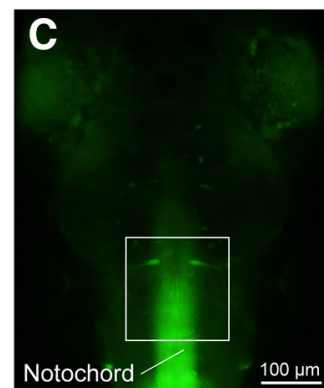
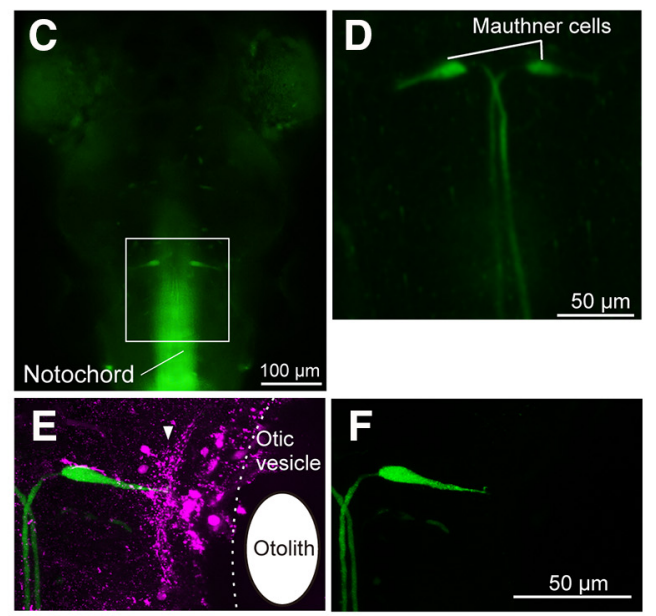

Figure 1. Mauthner cell-related networks that underlie the ASRs in zebrafish. $\boldsymbol{A}$, Schematic of $5 \mathrm{dpf}$ zebrafish larva viewed dorsally. Hair cells located in an otic vesicle relay auditory stimuli via the auditory nerve (data not shown) to Mauthner cells, a pair of large reticulospinal neurons that monosynaptically activate motor neurons in the spinal cord. $\boldsymbol{B}$, A detailed diagram of the ASR neural network. Open and filled shapes represent excitatory and inhibitory neurons, respectively. The auditory nerve provides excitatory input to feedforward inhibitory neurons and ipsilateral Mauthner cells through mixed excitatory chemical and electrical synapses (Mixed). Mauthner cells in turn activate contralateral spinal motor neurons, causing muscle contraction on one side. This enables the initial turn to escape away from the source of auditory stimulus. Glu, Excitatory glutamatergic synapse; Gly, inhibitory glycinergic synapse; Ach, cholinergic synapse. C, Gal4-induced GFP expression was observed in Mauthner neurons and notochord in Tg(hspGFFDMA130A); $T g(U A S: G F P)$ double-transgenic larvae. D, A magnified image of GFP expression in Tg(hspGFFDMA130A); Tg(UAS:GFP). E, F, Visualization of VIIIth nerve ( $\boldsymbol{E}$, magenta) and Mauthner cells $(\boldsymbol{E}, \boldsymbol{F}$, green). Note that GFP is expressed specifically in Mauthner cells.

adverse effects, they will often habituate to the sound and fail to show an ASR. As habituation represents a simple form of learning and memory, it has been extensively studied in animals ranging from jellyfish to humans (Thompson and Spencer, 1966; Kandel, 2001; Takahashi et al., 2008; Williams et al., 2013; Ramaswami, 2014; Wolman et al., 2015). A comparatively less characterized form of learning and memory that also decreases the probability of ASRs is behavioral desensitization, which differs from habituation in that the conditioning stimulus consists of repetitive auditory stimuli at levels insufficient to evoke an ASR (Oda et al., 1998). To gain insight into the molecular and cellular basis of sound-evoked behavioral desensitization, we and others have used fish, such as goldfish and zebrafish, because the neural circuity mediating the ASR is both simple and experimentally amenable.

In fish, fast ASRs are triggered by the initiation of a single action potential within Mauthner cells, a pair of large reticulospinal neurons located in rhombomere 4 of the hindbrain (Fig. 1A; Korn and Faber, 2005). Mauthner cells receive electrical and glutamatergic inputs from ipsilateral hair cells via the auditory nerve, and in turn make excitatory monosynaptic contacts with contralateral spinal motor neurons (Fig. 1B). In addition to connecting hair cells with Mauthner cells, the auditory nerve also activates glycinergic interneurons that provide bilateral feedforward inhibition to Mauthner cells to suppress their activation in response to subthreshold stimuli, as well as concurrent activation of ipsilateral Mauthner cell in response to suprathreshold stimuli. The simplicity of the ASR circuit has fostered its use for investigations into how neural circuits are modified by experience. For instance, while searching for evidence of long-term potentiation (LTP) at inhibitory synapses in adult goldfish, Korn et al. (1992) discovered that repetitive electrical stimulation of the VIII nerve, at amplitudes insufficient to activate ipsilateral Mauthner cells, nonetheless potentiated glycinergic transmission between feedforward inhibitory neurons and Mauthner cells. Subsequent efforts revealed that a more behaviorally relevant conditioning paradigm composed of repetitive audible tones, likewise insufficient in amplitude to activate Mauthner cells, also potentiated glycinergic transmission between feedforward inhibitory neurons and Mauthner cells (Oda et al., 1998). As potentiation of glycinergic transmission between these two neurons was found to coincide with a reduction in the ability to evoke an ASR in free-swimming goldfish, it represented one of the earliest demonstrations that inhibitory LTP at the cellular level could affect outcomes at the behavioral level.

In an attempt to better connect changes at the cellular level with changes at the behavioral level, we explored molecular mechanisms that might account for behavioral desensitization. To this end, we generated transgenic zebrafish whose Mauthner cells expressed fluorescently-tagged glycine receptors (GlyRs). Using these fish, we demonstrate that an increase in GlyR clustering in Mauthner cells is indispensable for and could induce sound-evoked behavioral desensitization. Furthermore, we show that GlyR clustering requires CaMKII-dependent phosphorylation of the postsynaptic scaffolding protein gephyrin at serine 325 , an event that acts as a molecular switch for increased binding between gephyrin and the $\beta$-loop of GlyR $\beta$ subunits. This CaMKII-dependent enhancement of synaptic GlyR clustering is a key molecular event for the induction of behavioral desensitization to sound.

\section{Materials and Methods}

Reagents. All compounds unless otherwise noted were purchased from Wako Pure Chemical Industries and used according to the manufacturer's guidelines. 
Animals. Zebrafish (Danio rerio) were bred and used in accordance with the Animal Care and Use Committee at Aoyama Gakuin University. Larvae were staged according to the established guidelines (Kimmel et al., 1995), and are given as either hours postfertilization or days postfertilization or (dpf). Tol2-mediated transgenesis (Kawakami, 2004) was used to establish the following transgenic lines: $\operatorname{Tg}(U A S: V e n u s-G l y R \alpha)$, $\operatorname{Tg}$ (UAS:Venus-Gephyrin), $\operatorname{Tg}($ UAS:mStrawberry-CAAX), $\mathrm{Tg}$ (UAS:mCherry), Tg(UAS:mCherry-2A-FLAG-CaMKII $\left.{ }_{K D}\right), \quad \operatorname{Tg}(U A S: m C h e r r y-2 A-F L A G-$ CaMKII $\left._{C A}\right), \operatorname{Tg}\left(U A S: F L A G-G e p h y r i n_{W T}-2 A-m\right.$ Cherry), and $\operatorname{Tg}(U A S$ : FLAG-Gephyrin ${ }_{S 325 D}-2 A-m$ Cherry). To restrict the expression of transgenes to Mauthner cells, the above transgenic lines were crossed with the Gal4 line $T g$ (hspGFFDMA130A) (Pujol-Martí et al., 2012). At the ages we examined, sex determination has not yet occurred in larval zebrafish.

Molecular biology. Codon optimized venus-tagged constructs were generated by adding cDNA encoding venus to the N-terminus of zebrafish gephyrin a cDNA (NM_001177444) that lacked the codon for the initial methionine (vGephyrin), and by inserting cDNA encoding venus inframe after residue 28 of zebrafish GlyR $\alpha 1$ (NM_131402), which corresponds to the end of the cleaved signal peptide ( $(\mathrm{G}$ GlyR $\alpha 1)$. Kinase dead (KD) and constitutively active (CA) isoforms of calcium/calmodulindependent protein kinase II (CaMKII) were generated by substitution of residue lysine 42 to methionine and residue threonine 286 to aspartate of zebrafish CaMKIIa (NM_001017741), respectively. Site-directed mutagenesis of CaMKII and gephyrin were performed using established laboratory procedures. Transgenes were ligated to the $2 \mathrm{~A}$ self-cleaving peptide and subcloned into pT2M for Tol2 transgenesis.

Electrophysiology. cRNA encoding GlyR $\alpha 1$, vGlyR $\alpha 1$, GlyR $\beta$ a, and GlyR $\beta$ b were made using an SP6 mMessage mMachine Kit. Xenopus laevis oocytes (Kitagawa Science Institute) were injected with 5 fmole of cRNA using a Nanoject II (Drummond Scientific), and incubated in Barth's solution at $\sim 17^{\circ} \mathrm{C}$ for $24-48 \mathrm{~h}$ before recordings. Borosilicate electrodes had resistances of $\sim 0.5 \mathrm{M} \Omega$ when filled with $3 \mathrm{M} \mathrm{KCl}$. Up to eight solutions were applied using a gravity-fed BPS-8 solution switcher while making two-electrode voltage-clamp recordings from oocytes held at $-50 \mathrm{mV}$ : (in mM) $90 \mathrm{NaCl}, 1 \mathrm{KCl}, 2 \mathrm{CaCl}_{2}, 1 \mathrm{MgCl}_{2}, 10 \mathrm{HEPES}, \mathrm{pH} 7.5$, with $\mathrm{NaOH}$, using a GeneClamp 500B amplifier controlled by pClamp 10 and a 1440A Digidata (Molecular Devices).

Rhodamine-dextran injection. Rhodamine-dextran with molecular weight 10,000 (ThermoFisher Scientific) was dissolved in PBS buffer. The Rhodamine-dextran solution was injected using glass needle poked into hindbrain close to otic vesicle in $4 \mathrm{dpf}$ zebrafish larvae that was anesthetized by tricaine methanesulfonate. Image of Mauthner cells and VIIIth nerve were captured $16 \mathrm{~h}$ after the rhodamine-dextran injection.

Immunostaining. Immunostaining of $5 \mathrm{dpf}$ zebrafish was performed as follows. Larvae were anesthetized in $0.02 \%(\mathrm{w} / \mathrm{v})$ tricaine methanesulfonate in system water, embedded in OCT compound (Sakura Finetek), and frozen in liquid nitrogen before sectioning $(20 \mu \mathrm{m})$ with a CM 3050 cryostat (Leica). Sections were fixed at RT in $4 \%(\mathrm{w} / \mathrm{v})$ paraformaldehyde for $30 \mathrm{~min}$ and then partially digested using $1 \mathrm{mg} / \mathrm{ml}$ pepsin in $0.2 \mathrm{~N} \mathrm{HCl}$ for $5 \mathrm{~min}$ at $37^{\circ} \mathrm{C}$. Processed sections were immunostained as previously described (Yamanaka et al., 2013) with the following primary antibodies at the indicated concentrations: anti-GlyR $\alpha$ (mAb4a, mouse $\operatorname{IgG}_{1}, 1: 1000$; Synaptic Systems), anti-gephyrin (Clone 45 , mouse $\operatorname{IgG}_{1}, 1: 1000$; BD Biosciences), anti-GFP (N86/8, mouse $\operatorname{IgG}_{2 \mathrm{a}}, 1: 4$; NeuroMab), anti-GFP (TP401, rabbit IgG, 1:1000; Torrey Pines Biolabs), anti-FLAG (FLA-1, mouse $\left.\operatorname{IgG}_{2 \mathrm{a}}, 1: 1000 ; \mathrm{MBL}\right)$. AlexaFluor 488-conjugated anti-mouse $\mathrm{IgG}_{1}$, AlexaFluor 488-conjugated anti-mouse $\mathrm{IgG}_{2 \mathrm{a}}$, AlexaFluor 555conjugated anti-mouse $\operatorname{IgG}_{1}$, and AlexaFluor 555-conjugated antimouse $\operatorname{IgG}_{2 \mathrm{a}}$, were used as secondary antibodies (1:1000; ThermoFisher Scientific).

Sample preparation for live imaging. To assess the effect of conditioning stimulus consist of repetitive subthreshold white noise pulses in the same individual, $5 \mathrm{dpf}$ transgenic larvae were embedded in $2 \%(\mathrm{w} / \mathrm{v})$ lowmelting agarose gel in system water without anesthesia. The quantification data of before and after of the conditioning are shown as Pre and Post, respectively. For other type assays, $5 \mathrm{dpf}$ transgenic larvae were anesthetized before being transferred to a $3 \%(\mathrm{w} / \mathrm{v})$ methyl cellulose solution.
Image capture. All samples, including immunolabeled sections and live transgenic larvae, were images using a TCS SP5 laser-scanning confocal microscope (Leica). Mauthner cell images were captured by frame averaged $(2 \times)$ optical slices $(x / y: 512 / 512, z: 0.5 \mu \mathrm{m})$ at $400 \mathrm{~Hz}$ using a $63 \times$ objective (HCX PL APO CS, NA 1.3, glycerol) with a pinhole diameter of $108 \mu \mathrm{m}$.

Quantification of the fluorescent images. All quantitative analyses of fluorescent signals were done using ImageJ software (NIH). The average fluorescence intensity of GFP in each Mauthner cells was calculated from GFP intensity in all optical slices (typically $\sim 30-40$ slices/Mauthner cell). To calculate the average fluorescence intensity of venus-tagged GlyR and Gephyrin, all venus-tagged protein clusters $(0.5-2 \mu \mathrm{m}$ diameter) on Mauthner cell surface were subjected for quantification as by Lévi et al., 2008. The mean fluorescence intensity of clusters in conditioned group was normalized by that in control group [relative fluorescent intensity (RFI)]. The fluorescence intensity of immunolabeled GlyR and gephyrin was quantified and normalized in the same manner.

Behavioral analysis. Subthreshold white noise (50 ms pulses at $90 \mathrm{dBa}$ every $10 \mathrm{~s}$ for $5 \mathrm{~min}$ ) generated using a UMA-BVS01 vibration speaker (Hanwha) controlled by Garage Band software (Apple) were delivered to $5 \mathrm{dpf}$ larvae in a $35 \mathrm{~mm}$ plastic dish affixed to an acrylic board. Suprathreshold stimuli were delivered to $5 \mathrm{dpf}$ larvae in 6 -well plates by hitting the plate using a BT-301 solenoid (MSA Factory). Motor behaviors were captured at $30 \mathrm{~Hz}$ using a Xacti camera (Sanyo) affixed to a stereomicroscope, and analyzed using QuickTime (Apple). Before conducting the ASR assay, we investigated whether our conditioning paradigm influences only the short latency responses. For this end, we recorded ASR before and after the exposure to the conditioning stimuli at $500 \mathrm{fps}$ using a high-speed camera HAS 200 (Ditect). Before exposure to the conditioning stimuli, half of all ASRs were short latency responses ( $<12 \mathrm{~ms})$, as defined previously (Burgess and Granato, 2007). These short-latency responses were eliminated after the conditioning, whereas the longlatency responses $(>16 \mathrm{~ms})$ were still observed. We also applied a Xacti video camera (Sanyo) that captures images at $30 \mathrm{~Hz}$, scored escape response within $33 \mathrm{~ms}$ ( 1 frame) of the stimulus as positive for an ASR and obtained the similar extent of decrease in response following conditioning. Thus, we assume that the ASR observation system using the Xacti video camera could show the decrease of the short latency response during the exposure to the conditioning stimuli. To reduce the amount of data capacity, we applied the Xacti video camera and analyzed escape response within $33 \mathrm{~ms}$ of the stimulus.

Biochemistry. The following constructs were generated and subcloned into pCS2 + expression vector: FLAG-tagged gephyrin, Myc-tagged gephyrin, HA-tagged CaMKII $\mathrm{CA}_{\mathrm{C}}$, HA-tagged $\mathrm{CaMKII}_{\mathrm{KD}}$, and GFP-tagged cytoplasmic loop of GlyR $\beta$ subunit (amino-acid residue 358-477). Expression vectors were transfected into HEK293T cells using Lipofectamine 2000 (ThermoFisher Scientific) according to the manufacturer's guidelines. Proteins were harvested $48 \mathrm{~h}$ after transfection using lysis buffer (in mM): $150 \mathrm{NaCl}, 50$ Tris-HCl, 2 EGTA, 1\% (v/v) Nonidet P-40, $50 \mathrm{NaF}, 1$ $\mathrm{Na}_{3} \mathrm{VO}_{4}, 1$ PMSF, 1 DTT, pH 7.5, with protease inhibitor cocktail (Nacalai Tesque). Coimmunoprecipitation of FLAG-tagged gephyrin and target proteins was performed using anti-Flag M2 affinity gel (SigmaAldrich) according to the manufacturer's guidelines. Isolated proteins were analyzed by Western blotting using the following antibodies at the indicated dilutions: anti-FLAG (FLA-1, mouse $\operatorname{IgG}_{2 \mathrm{a}}, 1: 1000$; MBL), anti-Myc (9E10, mouse $\operatorname{IgG}_{1}$, 1:1000; Santa Cruz Biotechnology), anti-HA (TANA2, mouse IgG Ig $_{2}, 1: 1000 ; \mathrm{MBL}$ ), anti-GFP (3E6, mouse $\operatorname{IgG}_{2 \mathrm{a}}$, 1:1000; ThermoFisher Scientific), and anti-GAPDH (6C5, mouse $\operatorname{IgG}_{1}, 1: 1000$; Acris). For detection, peroxidase-conjugated antimouse IgG and peroxidase-conjugated anti-rabbit IgG (G-21040, G-21234, 1:1000; ThermoFisher Scientific) were used with SuperSignal West Dura Chemiluminescent Substrate (Pierce). Signal intensities normalized to GAPDH were quantified using ImageJ (NIH). Mass spectrometrybased phosphorylation analysis of affinity purified FLAG-tagged gephyrin was performed as described previously (Nagai et al., 2016).

Experimental design and statistical analysis. Quantitative data were tested for normality by Shapiro-Wilk test $(p<0.05)$ to determine the types of statistical comparisons. The values were given as mean \pm SEM. All error bars in graphs represent the SEM values. Statistical significance 
Table 1. Venus-tagged GlyR $\alpha 1$ receptors are indistinguishable from their untagged counterparts

\begin{tabular}{|c|c|c|c|c|c|}
\hline \multirow[b]{2}{*}{ Receptor } & \multicolumn{2}{|l|}{ Glycine } & \multicolumn{3}{|l|}{ Strychnine } \\
\hline & $\mathrm{EC}_{50}, \mu \mathrm{M}$ & Hill coefficient & Glycine, $\mu \mathrm{m}$ & $\mathrm{IC}_{50}, \mathrm{nM}$ & Hill coefficient \\
\hline GlyR $\alpha 1$ & $100 \pm 6$ & $3.4 \pm 0.2$ & 50 & $15 \pm 3$ & $1.2 \pm 0.1$ \\
\hline vGlyR $\alpha 1$ & $104 \pm 8$ & $3.1 \pm 0.4$ & 50 & $19 \pm 4$ & $0.9 \pm 0.2$ \\
\hline GlyR $\alpha 1 / ß a$ & $191 \pm 11$ & $2.1 \pm 0.2$ & 200 & $15 \pm 6$ & $0.6 \pm 0.0$ \\
\hline vGlyR $\alpha 1 / ß a$ & $198 \pm 25$ & $2.4 \pm 0.4$ & 200 & $25 \pm 5$ & $0.8 \pm 0.2$ \\
\hline GlyR $\alpha 1 / \beta b$ & $212 \pm 22$ & $2.2 \pm 0.1$ & 200 & $45 \pm 9$ & $0.7 \pm 0.1$ \\
\hline vGlyR $\alpha 1 / \beta b$ & $194 \pm 19$ & $2.2 \pm 0.2$ & 200 & $26 \pm 2$ & $0.6 \pm 0.0$ \\
\hline
\end{tabular}

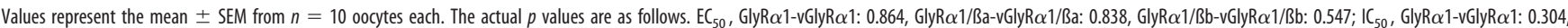
GlyR $\alpha 1 /$ ßa-vGlyR $\alpha 1 /$ Ba: 0.105, GlyR $\alpha 1 /$ ßb-vGlyR $\alpha 1 /$ Bb: 0.067.
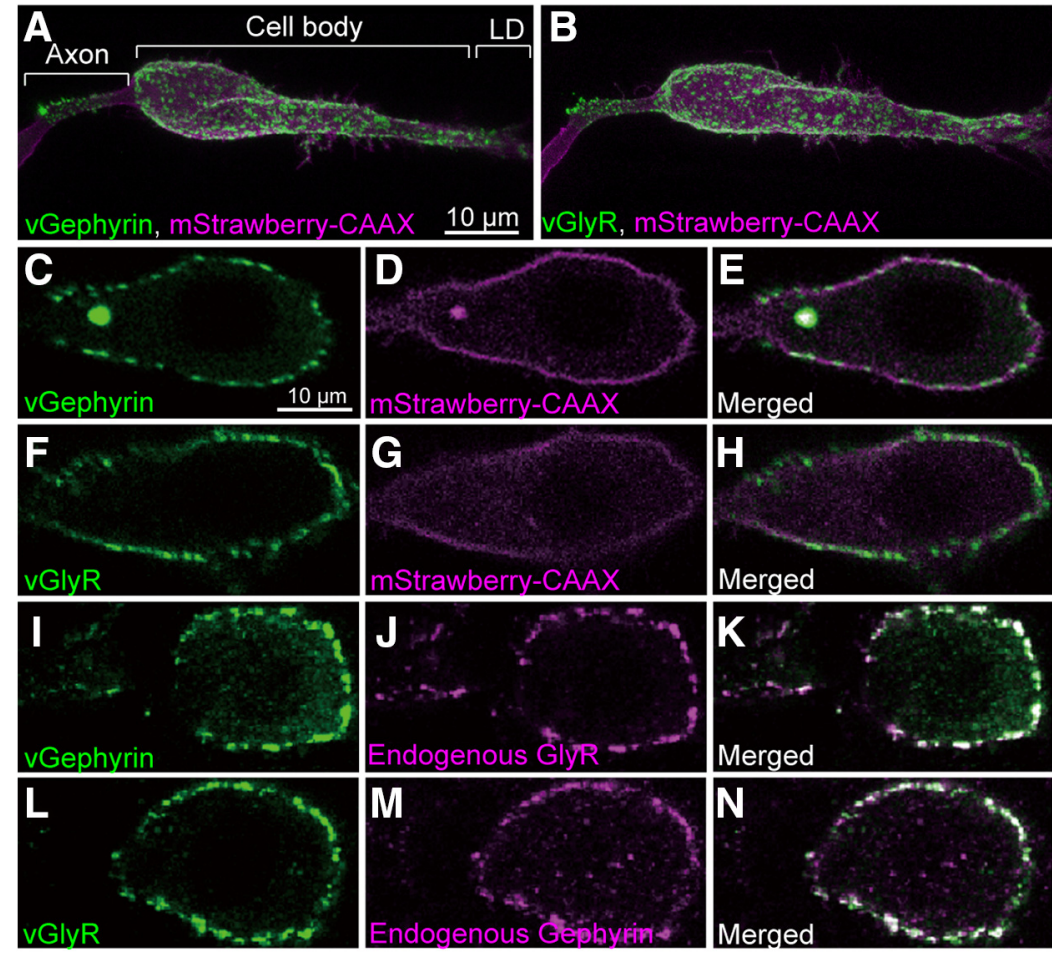

Figure 2. Venus-tagged gephyrin and GlyRs localize to the glycinergic synapses in Mauthner cells. $\boldsymbol{A}, \boldsymbol{B}$, Compressed z-stacks $(20 \mu \mathrm{m})$ of Mauthner cells from live $5 \mathrm{dpflarvae}$ expressing the membrane-targeted mStrawberry (mStrawberry-CAAX) and either venus (modified YFP)-tagged Gephyrin (vGephyrin; $\boldsymbol{A}$ ), or venus-tagged GlyR (vGlyR; $\boldsymbol{B}$ ). LD, Lateral dendrite. $\boldsymbol{C}-\boldsymbol{H}$, Representative images ( $0.5 \mu \mathrm{m}$ slice) of live Mauthner cells expressing membrane-bound mStrawberry and vGephyrin $(\boldsymbol{C}-\boldsymbol{E})$ orvGlyR $(\boldsymbol{F}-\boldsymbol{H}) . \boldsymbol{I}-\boldsymbol{N}$, Immunohistochemical images of Mauthner cells labeled by anti-GFP $(\boldsymbol{I}, \boldsymbol{K}, \mathrm{vGephyrin} ; \boldsymbol{L}, \boldsymbol{N}, \mathrm{vGlyR})$, anti-GlyR (J, $\boldsymbol{K}$, endogenous GlyR) and anti-gephyrin ( $\boldsymbol{M}, \boldsymbol{N}$, endogenous gephyrin). Note that vGephyrin and vGlyR colocalized with endogenous GlyR and gephyrin, respectively.

was determined using the two-tailed Student's $t$ test. Asterisks show $p$ value ranges: ${ }^{\star} p<0.05,{ }^{*} p<0.01,{ }^{* *} p<0.001$; nonsignificant (ns), $p>0.05$. The sample numbers are indicated in figure legends.

\section{Results}

Venus-tagged gephyrin and glycine receptors mimic their endogenous counterparts

Synaptic accumulation or clustering of neurotransmitter receptors is critical for efficient synaptic transmission. In glycinergic synapses, glycine receptors accumulate at synaptic sites through binding to gephyrin, a postsynaptic scaffolding protein (Tyagarajan and Fritschy, 2014). To assess the plasticity of glycinergic synapses in live zebrafish, we generated venus (modified YFP)tagged constructs of gephyrin and the glycine receptor $\alpha 1$ subunit (vGephyrin and vGlyR, respectively), the latter of which was electrophysiologically indistinguishable from untagged GlyRs when expressed in Xenopus oocytes (Table 1). To restrict the expression of these transgenes to Mauthner cells we used the Gal4 enhancer-trap line $T g(h s p G F F D M C 130 A$ ) (Pujol-Martí et al., 2012), in which Gal4 transcription factor is specifically expressed in Mauthner cells and notochord (Fig. 1C,D). To further confirm that Gal4 is not expressed in the auditory nerve, we injected rhodamine dextran into hindbrain of double transgenic $\mathrm{Tg}$ (hspGFFDMC130A); $\mathrm{Tg}(U A S: G F P)$ larvae and labeled VIIIth nerve afferents. We saw no GFP expression in the auditory nerve that contacts on a Mauthner cell (Fig. 1 E,F). Thus, this Gal4 enhancer-trap line allows us to induce transgene expression in Mauthner cells. Subsequent crosses with $\operatorname{Tg}(U A S$ : mStrawberry-CAAX) and either $\operatorname{Tg}(U A S$ : $v$ Gephyrin) or $\operatorname{Tg}(U A S: v G l y R \alpha 1)$ revealed the presence of both venus-tagged proteins at the membranes of Mauthner cells, notably the cell bodies, lateral dendrites, and proximal axons (Fig. $2 A, B$ ); a finding consistent with the previously reported distribution of endogenous GlyRs (Suwa et al., 2001; Koyama et al., 2011; Moly and Hatta, 2011). To more closely assess whether the venus-tagged constructs faithfully recapitulate the mobility of their endogenous counterparts, we performed immunohistochemical labeling of endogenous gephyrin and GlyRs. We found that vGephyrin and vGlyRs colocalized with endogenous gephyrin and GlyRs (Fig. 2C$N)$. Collectively, these results indicate that vGlyRs and vGephyrin mimic the mobility of their endogenous counterparts, and thereby allow for the real-time monitoring of these tagged proteins at glycinergic synapses in Mauthner cells.

\section{An increase in vGlyR clustering coincides with behavioral desensitization of the ASR}

To gain insight into the molecular mechanisms that underlie behavioral desensitization, we first established a suprathreshold "stimulation" delivered to $5 \mathrm{dpf}$ larvae in 6-well plates by hitting the plate using a solenoid hammer. This stimulation presented every $5 \mathrm{~s}$ for 20 times evoked non-habituating ASRs $(n=737 /$ 1000 pulses; 50 larvae). We also set up a "conditioning" sound that consists of $50 \mathrm{~ms}$ pulses of white noise presented at $90 \mathrm{dBa}$ every $10 \mathrm{~s}$ for $5 \mathrm{~min}$. Since the white noise did not induce ASRs ( $n=11 / 1050$ pulses; 35 larvae), it was available as conditioning paradigm. We found that suprathreshold stimuli-evoked ASRs were significantly reduced following conditioning in control lar- 

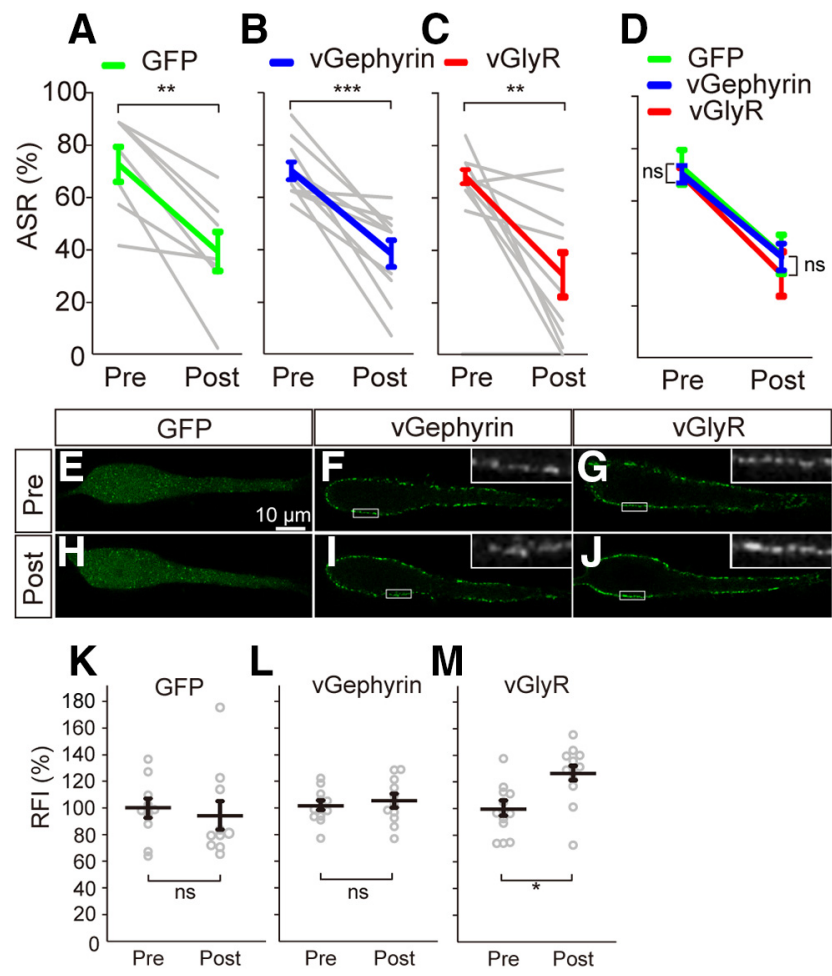

Figure 3. An increase in vGlyR clustering coincides with behavioral desensitization of the ASR. $\boldsymbol{A}-\boldsymbol{D}$, Gray lines indicate the responsiveness of individual larva to the suprathreshold stimulation before (Pre) and after conditioning (Post). Colored lines and error bars represent the average response \pm SEM of transgenic larvae in GFPlarvae $(\boldsymbol{A} ; n=7)$, vGephyrin larvae $(\boldsymbol{B} ; n=$ 10), and vGlyR larvae $(\boldsymbol{C} ; n=9)$. $\boldsymbol{D}$, An overlay graph of GFP, vGephyrin and vGlyR. $\boldsymbol{E}-\boldsymbol{J}$, Representative images ( $0.5 \mu \mathrm{m}$ slice here and afterward) of Mauthner cells expressing cytosolic GFP, vGephyrin, or vGlyR from control (Pre; $\boldsymbol{E}-\boldsymbol{G}$ ) and conditioned (Post) larvae $(\boldsymbol{H}-\boldsymbol{J})$. Boxed areas in $\boldsymbol{F}, \boldsymbol{G}, \boldsymbol{I}$, and $\boldsymbol{J}$ are enlarged at top right corner of each image. The enlarged images are shown in grayscale to emphasize the change in the fluorescent intensity. $\boldsymbol{K}-\boldsymbol{M}, \operatorname{RFI}$ from $\operatorname{GFP}(\boldsymbol{K} ; n=10)$, vGephyrin $(\boldsymbol{L} ; n=11)$, and vGlyR $(\boldsymbol{M} ; n=12)$ transgenic Mauthner cells. Different larvae were used in the control (Pre) and conditioned (Post) assay in $\boldsymbol{E}-\boldsymbol{M}$. Each open circle represents the average fluorescence intensity of an individual Mauthner cell compared with the normalized group average. Horizontal and vertical bars here and elsewhere represent the group average \pm SEM, respectively. The actual $p$ values are as follows. $\boldsymbol{A}, 0.0085 ; \boldsymbol{B}, 0.0002 ; \boldsymbol{C}, 0.0028 ; \boldsymbol{D}$, Pre GFP-vGephyrin: 0.756, GFP-vGlyR: 0.536, vGephyrin-vGlyR: 0.596; D, Post-GFP-vGephyrin: 0.948, GFP-vGlyR: 0.459, vGephyrin-vGlyR: 0.431; $\boldsymbol{K}, 0.719 ; \boldsymbol{L}, 0.546 ; \boldsymbol{M}, 0.022 .{ }^{* *} p<0.01$, ${ }^{* * *} p<0.001 ;$ ns, nonsignificant.

vae expressing GFP in Mauthner cells (Fig. 3A), indicating that our conditioning paradigm induced behavioral desensitization. In addition, we found that transgenic larvae expressing vGephyrin or vGlyR in Mauthner cells also exhibited a similar extent of behavioral desensitization (Fig. $3 B-D$ ), indicating that the expression of these transgenes did not overtly affect sensorimotor integration. Of note, close observation using a high speed camera ( $500 \mathrm{fps}$ ) revealed that most of the ASRs before conditioning were typical C-start with short latency $(<12 \mathrm{~ms})$ to the stimuli. After conditioning, the ASRs with short latency markedly decreased, whereas the long-latency responses $(>16 \mathrm{~ms}$ ) slightly diminished (data not shown), suggesting that the major parts of the ASRs eliminated by conditioning are short-latency responses.

To explore whether conditioning mobilized GlyR complexes in Mauthner cells, we compared vGephyrin or vGlyR clustering in control and conditioned larvae (Fig. $3 F, G, I, J$ ). This approach revealed that while the fluorescence intensity of vGephyrin clusters were similar between preconditioned (control) and postconditioned larvae (Fig. $3 L$ ), the intensity of vGlyR clusters was significantly increased in conditioned Mauthner cells (Fig. 3M).
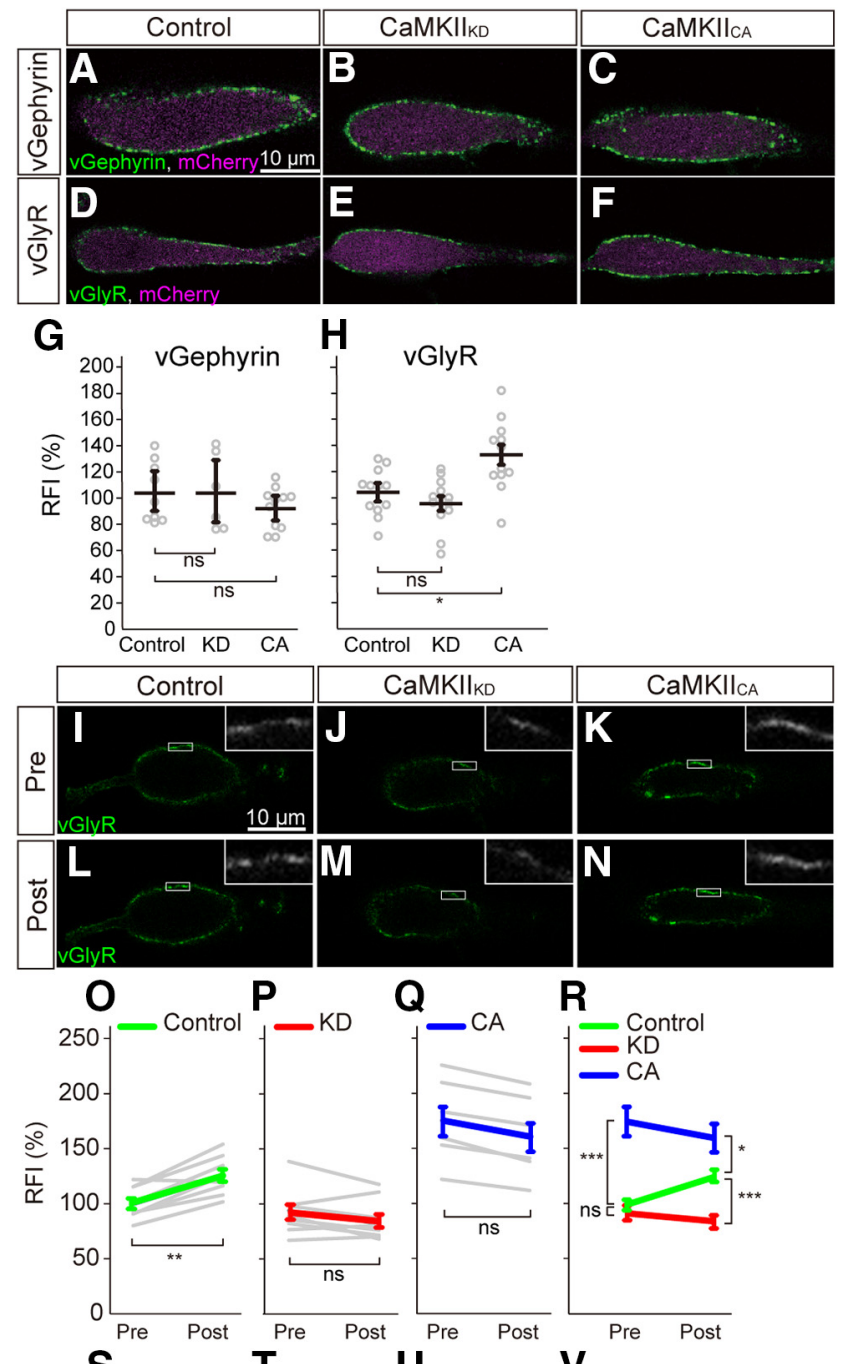

R Control

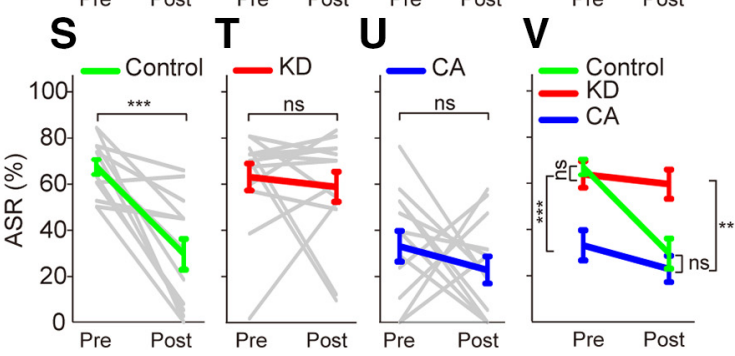

Figure 4. CaMKII activity was essential for the increase in GlyR clustering and the behaviora desensitization. $\boldsymbol{A}-\boldsymbol{F}$, Representative images of Mauthner cells from vGephyrin and vGlyR transgenic larvae coexpressing either mCherry alone (Control; $\boldsymbol{A}, \boldsymbol{D})$, mCherry with CaMKII $\mathrm{KD}_{\mathrm{D}}(\boldsymbol{B}, \boldsymbol{E})$, or mCherry with $\mathrm{CaMKI}_{\mathrm{CA}}(\boldsymbol{C}, \boldsymbol{F}), \boldsymbol{G}$, Effect of CaMKIl activity on vGephyrin RFl in larvae from Control $(n=9)$, CaMKII $_{\mathrm{KD}}(n=6)$, and CaMKII ${ }_{\mathrm{CA}}(n=11) . \boldsymbol{H}$, Effect of CaMKII activity on vGlyR RFIs in larvae from Control $(n=12)$, CaMKII $_{\mathrm{KD}}(n=12)$, and CaMKII ${ }_{\mathrm{CA}}(n=12)$. I-N, Representative images of the same Mauthner cell before and after conditioning from vGlyR transgenic larvae coexpressing either mCherry alone (Control; $\boldsymbol{I}, \boldsymbol{L})$, mCherry with CaMKII $\left.\mathrm{KD}_{(\boldsymbol{J}}, \boldsymbol{M}\right)$, or mCherry with $\mathrm{CaMKII}_{\mathrm{CA}}(\boldsymbol{K}, \boldsymbol{N})$. Boxed areas in $\boldsymbol{I}-\boldsymbol{N}$ are enlarged at top right corner of each images. The enlarged images are shown in grayscale to emphasize the change in the fluorescent intensity. $\boldsymbol{0}-\boldsymbol{R}$, Effect of CaMKII activity on vGlyR RFI in control $(\boldsymbol{0} ; n=9), \mathrm{CaMKII}_{\mathrm{KD}}(\boldsymbol{P} ; n=9)$, and CaMKII $_{\mathrm{CA}}(\boldsymbol{Q} ; n=7)$. $\boldsymbol{R}$, An overlay graph of control, CaMKII ${ }_{\mathrm{KD}}$, and $\mathrm{CaMKII}_{\mathrm{CA}}$. $\boldsymbol{S}-\boldsymbol{V}$, Effect on CaMKIl activity and on ASR in control $(\boldsymbol{S} ; n=13), \mathrm{CaMKI}_{\mathrm{KD}}(\boldsymbol{T} ; n=13)$, and $\mathrm{CaMKII}_{\mathrm{CA}}(\boldsymbol{U} ; n=$ 13). $\boldsymbol{V}$, An overlay graph of control, $\mathrm{CaMKII}_{\mathrm{KD}}$, and $\mathrm{CaMKII}_{\mathrm{CA}}$. The actual $p$ values are as follows. G, Control-CaMKII ${ }_{\mathrm{KD}}: 0.994$, Control-CaMKII $\mathrm{CA}: 0.212 ; \boldsymbol{H}$, Control-CaMKII $\mathrm{KD}_{\mathrm{R}}: 0.431$, Control-CaM$\mathrm{KII}_{\mathrm{CA}}: 0.0107 ; \mathbf{O}, 0.0040 ; \boldsymbol{P}, 0.431 ; \mathbf{Q}: 0.449 ; \boldsymbol{R}$, Pre-Control-CaMKII $\mathrm{KD}_{0}: 0.336$, Control-CaMKII ${ }_{\mathrm{CA}}$ : $0.0008 ; \boldsymbol{R}$, Post-Control-CaMKII $\mathrm{KD}_{\mathrm{D}}: 0.0001$, Control-CaMKII $\mathrm{CA}: 0.0315 ; \boldsymbol{S}, 0.0001 ; \boldsymbol{T}, 0.638 ; \boldsymbol{U}$, 0.267; V, Pre-Control-CaMKII ${ }_{\mathrm{KD}}: 0.642$, Control-CaMKII $\mathrm{CA}_{0}: 0.0003 ; \boldsymbol{V}$, Post-Control-CaMKII ${ }_{\mathrm{KD}}$ 0.0039 , Control-CaMKII ${ }_{\mathrm{CA}}: 0.468 .{ }^{*} p<0.05,{ }^{* *} p<0.01,{ }^{* * *} p<0.001$; ns, nonsignificant. 
A

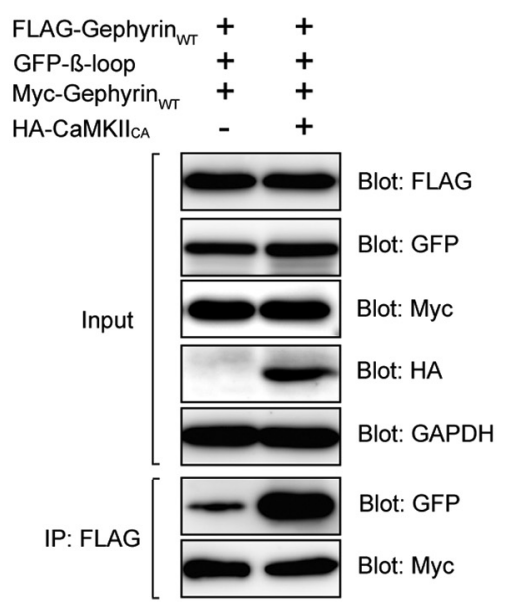

B

B

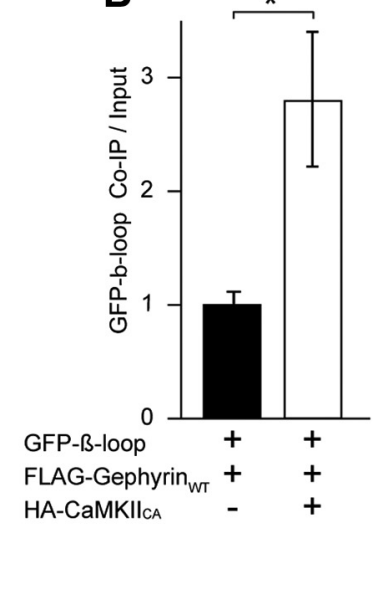

C

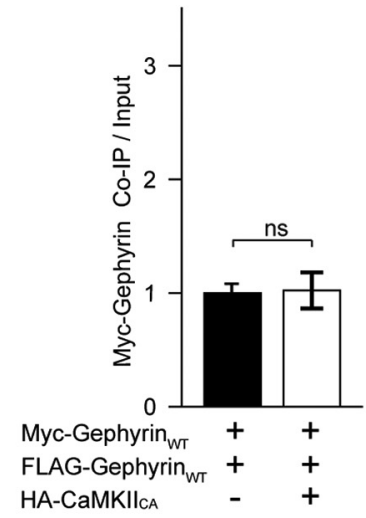

Figure 5. CaMKII promotes the interaction between gephyrin and the $\beta$-loop of GlyR $\beta$ subunits. A, Protein extracts from HEK293T cells transfected with FLAG-tagged gephyrin, Myc-tagged

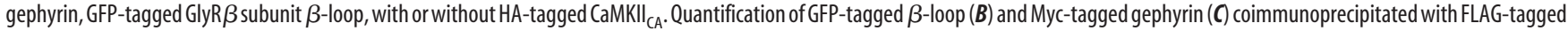

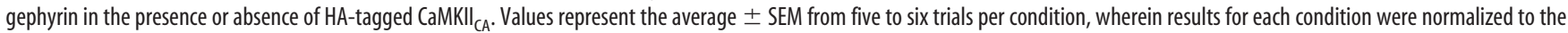
amount of $\beta$-loop or Myc-tagged gephyrin coimmunoprecipitated with FLAG-tagged gephyrin in the absence of HA-tagged CaMKII ${ }_{\text {CA }}$. The actual $p$ values are as follows. $\boldsymbol{B}, 0.0158 ; \boldsymbol{C}, 0.893$. ${ }^{*} p<$ $0.05 ;$ ns, nonsignificant.

Of note, as the intensity of cytosolic GFP was indistinguishable between preconditioned and post-conditioned larvae (Fig. $3 E, H, K$ ), the increase in vGlyR clusters likely reflects a redistribution of pre-existing receptors enabling fluorescent detection over the threshold rather than de novo synthesis of receptors. Thus desensitization of the ASR in zebrafish larvae coincides with an increase in vGlyR clustering in Mauthner cells.

CaMKII activity is essential for the increase in GlyR clustering and behavioral desensitization

To examine whether the mobilization of vGlyRs passively coincides with, or actively underlies behavioral desensitization, we first developed a genetically-based method to control vGlyR clustering in Mauthner cells. In brief, pharmacological inhibition of CaMKII in zebrafish was previously shown to reduce endogenous GlyR clusters in Mauthner cells (Yamanaka et al., 2013). Armed with this knowledge, we generated transgenic larvae whose Mauthner cells expressed either a KD isoform $\left(\mathrm{CaMKII}_{\mathrm{KD}}\right)$ or a CA isoform $\left(\mathrm{CaMKII}_{\mathrm{CA}}\right.$ ) of CaMKII by Gal4-UAS method. These CaMKII transgenes also bore an N-terminal mCherry tag separated by the auto-cleave peptide sequence $2 \mathrm{~A}$ (mCherry-2ACaMKII), which results in the equal production of mCherry and untagged CaMKII from a single mRNA transcript (Kim et al., 2011).

Before white-noise conditioning, clusters of vGephyrin and vGlyRs were again observed in Mauthner cells from CaMKIItransgenic larvae (Fig. $4 A-F$ ). A closer examination revealed that the clustering of vGephyrin was indistinguishable between control (mCherry) and CaMKII-transgenic larvae (Fig. 4G), indicating that the gephyrin framework was largely unaltered by CaMKII activity. Although CaMKII $\mathrm{KD}_{\mathrm{N}}$ did not affect vGlyR clustering, CaMKII $_{\mathrm{CA}}$ significantly increased vGlyR clustering in Mauthner cells (Fig. 4H), reminiscent of condition-evoked clustering.

We next explored the effect of conditioning on vGlyR clustering in CaMKII transgenic larvae. To this end, we imaged vGlyR clustering in the same Mauthner cell before and after conditioning. As before, we observed that conditioning significantly increased vGlyR clustering in control larvae (Fig. 4I, L,O). On the other hand, vGlyR clustering in $\mathrm{CaMKII}_{\mathrm{KD}}$ larvae failed to un- dergo a significant increase in response to conditioning (Fig. $4 J, M, P)$. Finally, the clustering of vGlyRs in $\mathrm{CaMKII}_{\mathrm{CA}}$ larvae, which was again found to be significantly elevated before conditioning, was unchanged by conditioning (Fig. $4 K, N, Q$ ). Thus elevated CaMKII activity increases vGlyR clustering independent of auditory conditioning, while inhibition of CaMKII activity blocks condition-evoked increases in vGlyR clustering (Fig. 4R).

If GlyR clustering in Mauthner cells underlies behavioral desensitization of the ASR, then blocking the conditioned-evoked increase in vGlyR clustering $\left(\mathrm{CaMKII}_{\mathrm{KD}}\right)$ should prevent desensitization. Likewise, zebrafish larvae with pre-elevated levels of vGlyR clusters $\left(\mathrm{CaMKII} \mathrm{CA}_{\mathrm{CA}}\right)$ would be expected to exhibit reduced ASRs in the absence of conditioning. In agreement with these predictions, we found that $\mathrm{CaMKII}_{\mathrm{KD}}$ larvae exhibited a similar high level of ASRs before and after conditioning, while CaMKII ${ }_{\mathrm{CA}}$ larvae displayed a similar low level of ASRs before and after conditioning (Fig. 4S-V). Collectively, these results demonstrate that GlyR clustering in Mauthner cells governs behavioral sensitization of the ASR in zebrafish.

\section{CaMKII-dependent phosphorylation of gephyrin at serine 325 drives GlyR clustering and behavioral desensitization to sound}

The clustering of GlyRs is dependent upon the homo-multimeric scaffolding protein gephyrin (Ogino et al., 2011). Previous research has also found that the interaction of GlyRs with gephyrin is mediated by the second cytoplasmic loop of GlyR $\beta$ subunits, commonly referred to as the $\beta$-loop (Meyer et al., 1995). To elucidate whether an increase in CaMKII activity promotes binding between gephyrin and the $\beta$-loop of GlyR $\beta$ subunits, we performed coimmunoprecipitation assays of HEK293 cell lysates. We found that coexpression of CaMKII $_{\mathrm{CA}}$ significantly increased binding between FLAG-tagged gephyrin and GFP-tagged $\beta$-loop of GlyR $\beta$ subunit (Fig. $5 A, B$ ), whereas the extent of binding between gephyrin molecules was unaffected (Fig. $5 A, C$ ). Thus elevated CaMKII activity promotes binding between gephyrin and GlyRs.

To gain insight into the molecular basis by which an increase in CaMKII activity promotes the interaction between gephyrin 
A

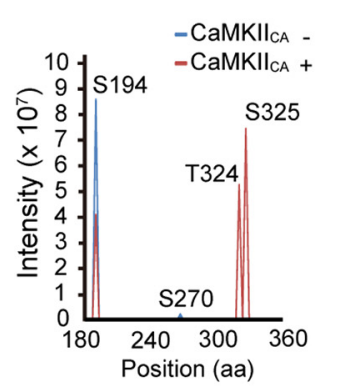

B

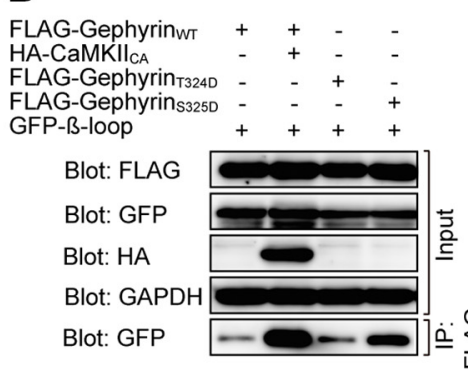

C

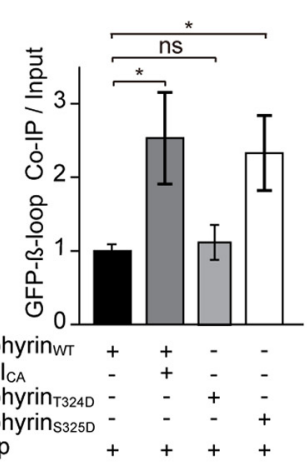

FLAG-Gephyrin

(1) HA-CaMKII

FLAG-Gephyrin ${ }_{T 324 D}$

FLAG-Gephyrin ${ }_{\$ 3250}$ GFP-B-Ioop
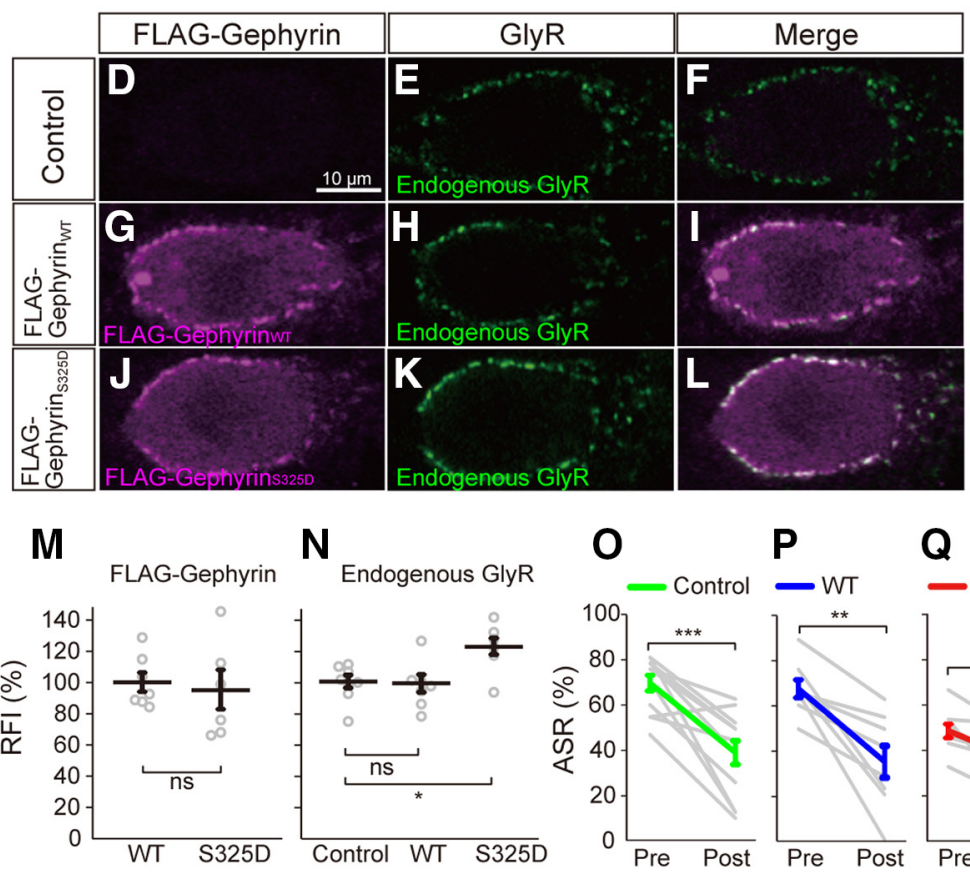

$\mathbf{P}$

$$
\text { . }
$$




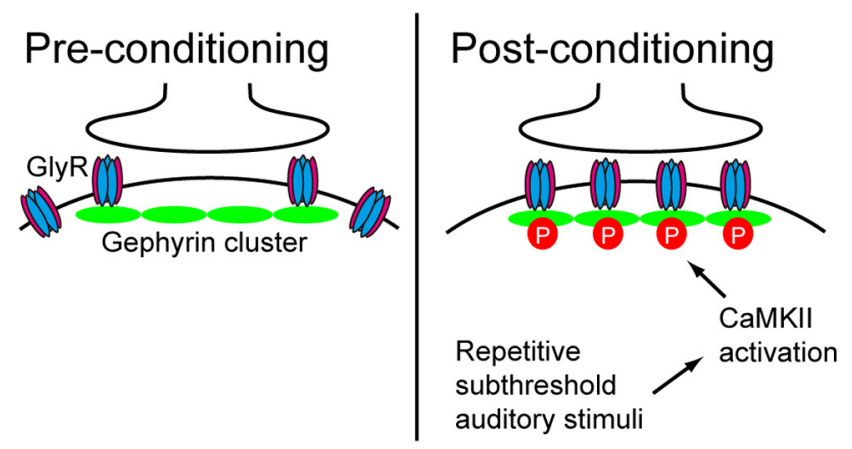

Figure 7. Schematic model of subthreshold sound-induced GlyR clustering at postsynaptic site. GlyR moves into and out of synapse by lateral diffusion. Before conditioning, GlyR molecules exist at postsynaptic sites at low level. Following repetitive exposure to subthreshold auditory stimuli, CaMKII is activated in Mauthner cells that results in phosphorylation of gephyrin at serine 325. This phosphorylation increases binding between gephyrin and GlyR and thus enhances anchoring of GlyRs at postsynaptic sites. As a consequence, GlyR accumulates at postsynaptic sites.

Mauthner cells (Fig. $6 N$ ); a result consistent with our immunoprecipitation findings from HEK293 cells. Of note, an overall increase in the expression of gephyrin is unlikely, given that GlyR clustering in gephyrin ${ }_{\mathrm{WT}}$ larvae was similar to control larvae (Fig. $6 M)$. We also examined whether the gephyrin ${ }_{\mathrm{S} 325 \mathrm{D}}$-induced clustering of endogenous GlyR is sufficient to attenuate ASRs. As expected, we found that gephyrin ${ }_{\mathrm{S} 325 \mathrm{D}}$ larvae exhibited reduced preconditioned ASRs compared with both gephyrin ${ }_{\mathrm{WT}}$ and control larvae (Fig. 6O-R).

Together, our results suggest a model wherein repetitive subthreshold auditory stimuli leads to an increase in CaMKII activity that results in phosphorylation of gephyrin at serine 325 in Mauthner cells. This gephyrin phosphorylation acts as a molecular switch to enhance gephyrin-GlyR binding and subsequent clustering of GlyR at inhibitory synapse, thereby enabling behavioral desensitization (Fig. 7).

\section{Discussion}

Our present study began with a desire to better understand how changes at the molecular and cellular levels underlie changes at the network and behavioral levels. In this pursuit, we explored whether the mobilization of GlyRs in zebrafish Mauthner cells contributes to behavioral desensitization to sound, and if so, what then governs the mobility of GlyRs. Our efforts revealed that CaMKII-dependent phosphorylation of the scaffolding protein gephyrin at serine 325 promotes binding with GlyR, and subsequent clustering of GlyRs in Mauthner cells, which is indispensable for and could induce for behavioral desensitization.

\section{Gephyrin phosphorylation as a molecular switch for GlyR clustering enhancement}

Gephyrin was originally copurified as a $93 \mathrm{kDa}$ polypeptide during the initial isolation of endogenous GlyRs from rat spinal cords (Pfeiffer et al., 1982). Following the cloning and identification of gephyrin as a microtubule-associated scaffolding protein (Kirsch et al., 1991; Prior et al., 1992), subsequent studies have focused on the molecular and cellular aspects of gephyrin's function at inhibitory synapse (Charrier et al., 2010; Wuchter et al., 2012). Gephyrin has been thought to form a huge multimer through trimerization of $\mathrm{N}$-terminal domain and dimerization of C-terminal domain at inhibitory postsynaptic synapses (Fritschy et al., 2008). The synaptic GlyR, which is a heteropentamer of $\alpha$ and $\beta$ subunits, accumulates at inhibitory synapses through binding to the gephyrin scaffold (Choquet and Triller, 2013). Our efforts have logically expanded upon these previous findings and revealed that the affinity of GlyRs for a passive gephyrin framework is also the primary determinant of the synaptic GlyR density in vivo. Furthermore, we also demonstrated that the affinity of GlyRs for a gephyrin is governed by the phosphorylation state of serine 325 of gephyrin, which is determined by the level of CaMKII activity. Although $>20$ phosphorylation sites on gephyrin have been previously identified (Fritschy et al., 2008; Choquet and Triller, 2013), the phosphorylation of serine 325 has not been reported. Although therefore novel, our findings do not indicate whether CaMKII directly phosphorylates the serine residue or exerts its effect through an intermediary kinase. In this study, we applied Gal4-UAS-based mis-expression of CaMKII variants in Mauthner cells. Because endogenous expression of CaMKII is likely unaffected, the limitation of our exogenous CaMKII expression should be noted for interpretation. A recent structural study has suggested that a hydrogen bond between aspartate 327 of gephyrin and the $\beta$-loop of GlyR $\beta$ subunits is critical for gephyrin-GlyR binding (Maric et al., 2014). As serine 325 is two amino acids prior, the phosphorylation of serine 325 may alter the local conformation of gephyrin to better accommodate hydrogen bonding with the $\beta$-loop of GlyR $\beta$ subunits. If so, the phosphorylation state of serine 325 might represent a common mechanism to determine the number of synaptic GlyRs in all vertebrates, because serine 325 is completely conserved among vertebrates (Ogino et al., 2011). Likewise, as the portion of gephyrin is thought to mediate the binding between gephyrin and $\mathrm{GABA}_{\mathrm{A}}$ receptors (Maric et al., 2014), the phosphorylation state of serine 325 might also serve as a molecular switch for the clustering of $\mathrm{GABA}_{\mathrm{A}}$ receptors and thus decision-making in higher brain regions (Hennequin et al., 2017).

\section{The possible molecular basis underlying CaMKII activation following auditory stimuli}

Although our study showed that CaMKII activation is involved in the desensitization of the ASR, how does exposure to repetitive subthreshold auditory stimuli give rise to the increase of intracellular $\mathrm{Ca}^{2+}$ for CaMKII activation in Mauthner cells? It has been reported in both glutamatergic and GABAergic synapses that CaMKII is activated by $\mathrm{Ca}^{2+}$ influx via NMDA receptors, and that activated CaMKII plays a central role in the induction of LTP, suggesting a shared function for synaptic plasticity in excitatory and inhibitory synapses (Citri and Malenka, 2008; Marsden et al., 2010; Lüscher and Malenka, 2012). Marsden et al. (2007, 2010) have proposed a hypothesis that the difference in the amount of $\mathrm{Ca}^{2+}$ influx mediated by NMDA receptor is a critical factor to determine whether excitatory or inhibitory synapse is potentiated. In their experiments using cultured hippocampal neurons, application of $100 \mu \mathrm{M}$ glutamate induced larger $\mathrm{Ca}^{2+}$ influx than that of $10 \mu \mathrm{M}$ glutamate or $50 \mu \mathrm{M}$ NMDA. Intriguingly, the moderate $\mathrm{Ca}^{2+}$ influx following NMDA application that failed to evoke action potential-induced CaMKII translocation to the inhibitory synapse, and in turn increased $\mathrm{GABA}_{\mathrm{A}}$ receptor expression at the cell surface (Marsden et al., 2007, 2010). Similarly, synaptic accumulation of GlyRs is enhanced by NMDA receptor activation in cultured spinal neurons (Lévi et al., 2008). We used repetitive subthreshold auditory stimuli to induce GlyR clustering. Given that Mauthner cells simultaneously receive glutamatergic excitatory inputs that include NMDA receptor-mediated transmission and glycinergic inhibitory inputs following auditory nerve excitation (Korn and Faber, 2005), the subthreshold auditory stimuli may evoke moderate $\mathrm{Ca}^{2+}$ in- 
flux via NMDA receptor and trigger CaMKII activation in Mauthner cells. Marsden et al. revealed that activation of NMDA receptors induces phosphorylation of CaMKII at threonine 286 (T286) and localization of CaMKII at inhibitory synapses. Our finding that the constitutive-active isoform of CaMKII, which was generated by a phosphomimetic T286D mutation, enhanced GlyR clustering in Mauthner cells is consistent with Marsden's results. These data collectively suggest that repetitive subthreshold auditory stimuli may active CaMKII by a moderate increase of intracellular $\mathrm{Ca}^{2+}$ through NMDA receptor activation.

\section{Relevance to humans and other forms of learning and memory}

Although Mauthner cells are common to fish and amphibians, giant neurons of the caudal pontine reticular nucleus $(\mathrm{PnC})$ in mammals have been shown to possess many Mauthner cell-like attributes. First, PnC giant neurons receive monosynaptic inputs from the cochlear nerve, and in turn make monosynaptic outputs to motor neurons in the spinal cord (Lingenhöhl and Friauf, 1994). Second, electrophysiological recordings, coupled with immunohistochemical labeling, indicated that most PnC giant neurons express GlyRs (Koch and Friauf, 1995; Geis and Schmid, 2011). Third, lesion experiments revealed that PnC giant neurons are required for normal ASRs (Koch et al., 1992) as in the case of Mauthner cells (Kohashi and Oda, 2008). Finally, pharmacological blockade of glycinergic transmission by strychnine lowered the ASR threshold in fish (Oda et al., 1998), and exacerbate the ASR in rats (Koch and Friauf, 1995), possibly through a similar disinhibition of Mauthner cells and giant neurons. However, the physiological significance of the glycinergic inhibition on $\mathrm{PnC}$ giant neurons in behavioral changes, such as habituation and desensitization to sound has not been elucidated. The fish Mauthner cell circuit is quite simple compared with the mammalian PnC network, which includes dozens of giant neurons (Koch and Friauf, 1995; Korn and Faber, 2005; Geis and Schmid, 2011). This simplicity is the advantage to use zebrafish for investigation of the molecular and cellular basis of the ASR modulation.

Similar to the behavioral desensitization, zebrafish larvae show habituation to repetitive sound stimuli. Wolman et al. (2015) have identified that IGF signaling molecules such as IGF receptor and a secreted protein PAPPA are involved in inducing habituation. These IGF signaling molecules may also be related to the behavioral desensitization.

Prepulse inhibition is another case in reduction of acoustic response, in which a subthreshold stimulus inhibits the behavioral reaction of the animal to a subsequent suprathreshold stimulus (Braff et al., 1978; Swerdlow et al., 2001; Burgess and Granato, 2007). A recent work revealed that suppression of glutamate release from VIIIth nerves to Mauthner cells is a key basis for the auditory-induced prepulse inhibition in zebrafish (Tabor et al., 2018). Thus, this prepulse inhibition is mediated by presynaptic modulation and is different from behavioral desensitization that is induced by postsynaptic receptor modulation.

\section{Model underlying behavioral desensitization to sound}

We proposed a molecular mechanism triggering behavioral desensitization. The exposure of zebrafish larvae to repetitive subthreshold sound induces phosphorylation of gephyrin at serine 325 via CaMKII activation in Mauthner cells. This modification enhances binding between gephyrin and GlyR, and propels synaptic accumulation of GlyR. Subsequently, the reinforcement of inhibitory glycinergic transmission could suppress suprathreshold stimulus-induced Mauthner cell excitation and thus diminish
ASRs, leading to behavioral desensitization. By taking advantages of genetic manipulation of Mauthner cells, receptor visualization and behavioral assay, future study of desensitization will further reveal its detailed molecular basis such as $\mathrm{Ca}^{2+}$ source and recovery from the desensitization.

\section{Significance of behavioral desensitization to sound}

In wild, fish are sensitive to water splash. Upon hearing a splash, they execute a rapid escape behavior, probably because they have to dodge bird attack diving into water, which comes immediately after splash. In rainy weather, however, birds cannot see underwater fish and give up hunting. If so, fish should cease responding to splash when they hear rainfall. In this study, we used white noise as conditioning auditory stimuli, because it was most effective for inducing behavioral desensitization compared with any other tones (data not shown). White noise is a mixed sound of all the frequencies between 20 and $20,000 \mathrm{~Hz}$ and is exactly the same with the sound of rainfall. We thus assume that behavioral desensitization to white noise is useful for adaptation to weather change. Interestingly, aquatic animals, such as fish and amphibians, have M-cells, while land animals do not. It is probably because aquatic animals can sense bird attack by splash before the physical contact, whereas land animals cannot detect it anyway in advance. Then, land animals might have ceased to maintain the M-cells.

\section{References}

Braff D, Stone C, Callaway E, Geyer M, Glick I, Bali L (1978) Prestimulus effects on human startle reflex in normals and schizophrenics. Psychophysiology 15:339-343.

Burgess HA, Granato M (2007) Sensorimotor gating in larval zebrafish. J Neurosci 27:4984-4994.

Charrier C, Machado P, Tweedie-Cullen RY, Rutishauser D, Mansuy IM, Triller A (2010) A crosstalk between betal and beta3 integrins controls glycine receptor and gephyrin trafficking at synapses. Nat Neurosci 13: $1388-1395$.

Choquet D, Triller A (2013) The dynamic synapse. Neuron 80:691-703.

Citri A, Malenka RC (2008) Synaptic plasticity: multiple forms, functions, and mechanisms. Neuropsychopharmacology 33:18-41.

Fritschy JM, Harvey RJ, Schwarz G (2008) Gephyrin: where do we stand, where do we go? Trends Neurosci 31:257-264.

Geis HR, Schmid S (2011) Glycine inhibits startle-mediating neurons in the caudal pontine reticular formation but is not involved in synaptic depression underlying short-term habituation of startle. Neurosci Res 71:114123.

Hennequin G, Agnes EJ, Vogels TP (2017) Inhibitory plasticity: balance, control, and codependence. Annu Rev Neurosci 40:557-579.

Kandel ER (2001) The molecular biology of memory storage: a dialogue between genes and synapses. Science 294:1030-1038.

Kawakami K (2004) Transgenesis and gene trap methods in zebrafish by using the Tol2 transposable element. Methods Cell Biol 77:201-222.

Kim JH, Lee SR, Li LH, Park HJ, Park JH, Lee KY, Kim MK, Shin BA, Choi SY (2011) High cleavage efficiency of a 2A peptide derived from porcine teschovirus-1 in human cell lines, zebrafish and mice. PLoS One 6:e18556.

Kimmel CB, Ballard WW, Kimmel SR, Ullmann B, Schilling TF (1995) Stages of embryonic development of the zebrafish. Dev Dyn 203:253-310.

Kirsch J, Langosch D, Prior P, Littauer UZ, Schmitt B, Betz H (1991) The 93-kDa glycine receptor-associated protein binds to tubulin. J Biol Chem 266:22242-22245.

Koch M, Friauf E (1995) Glycine receptors in the caudal pontine reticular formation: are they important for the inhibition of the acoustic startle response? Brain Res 671:63-72.

Koch M, Lingenhöhl K, Pilz PK (1992) Loss of the acoustic startle response following neurotoxic lesions of the caudal pontine reticular formation: possible role of giant neurons. Neuroscience 49:617-625.

Kohashi T, Oda Y (2008) Initiation of Mauthner- or non-Mauthnermediated fast escape evoked by different modes of sensory input. J Neurosci 28:10641-10653. 
Korn H, Faber DS (2005) The Mauthner cell half a century later: a neurobiological model for decision-making? Neuron 47:13-28.

Korn H, Oda Y, Faber DS (1992) Long-term potentiation of inhibitory circuits and synapses in the central nervous system. Proc Natl Acad Sci U S A 89:440-443.

Koyama M, Kinkhabwala A, Satou C, Higashijima Si, Fetcho J (2011) Mapping a sensory-motor network onto a structural and functional ground plan in the hindbrain. Proc Natl Acad Sci U S A 108:1170-1175.

Lévi S, Schweizer C, Bannai H, Pascual O, Charrier C, Triller A (2008) Homeostatic regulation of synaptic GlyR numbers driven by lateral diffusion. Neuron 59:261-273.

Lingenhöhl K, Friauf E (1994) Giant neurons in the rat reticular formation: a sensorimotor interface in the elementary acoustic startle circuit? J Neurosci 14:1176-1194.

Lüscher C, Malenka RC (2012) NMDA receptor-dependent long-term potentiation and long-term depression (LTP/LTD). Cold Spring Harb Perspect Biol 4:a005710.

Maric HM, Kasaragod VB, Hausrat TJ, Kneussel M, Tretter V, Strømgaard K, Schindelin H (2014) Molecular basis of the alternative recruitment of GABA(A) versus glycine receptors through gephyrin. Nat Commun 5:5767.

Marsden KC, Beattie JB, Friedenthal J, Carroll RC (2007) NMDA receptor activation potentiates inhibitory transmission through GABA receptorassociated protein-dependent exocytosis of $\mathrm{GABA}_{\mathrm{A}}$ receptors. J Neurosci 27:14326-14337.

Marsden KC, Shemesh A, Bayer KU, Carroll RC (2010) Selective translocation of $\mathrm{Ca}^{2+} /$ calmodulin protein kinase $\mathrm{II} \alpha(\mathrm{CaMKII} \alpha)$ to inhibitory synapses. Proc Natl Acad Sci U S A 107:20559-20564.

Meyer G, Kirsch J, Betz H, Langosch D (1995) Identification of a gephyrin binding motif on the glycine receptor $\beta$ subunit. Neuron 15:563-572.

Moly PK, Hatta K (2011) Early glycinergic axon contact with the Mauthner neuron during zebrafish development. Neurosci Res 70:251-259.

Nagai T, Nakamuta S, Kuroda K, Nakauchi S, Nishioka T, Takano T, Zhang X, Tsuboi D, Funahashi Y, Nakano T, Yoshimoto J, Kobayashi K, Uchigashima M, Watanabe M, Miura M, Nishi A, Kobayashi K, Yamada K, Amano M, Kaibuchi K (2016) Phosphoproteomics of the dopamine pathway enables discovery of Rap1 activation as a reward signal in vivo. Neuron 89:550-565.

Oda Y, Kawasaki K, Morita M, Korn H, Matsui H (1998) Inhibitory longterm potentiation underlies auditory conditioning of goldfish escape behaviour. Nature 394:182-185.

Ogino K, Ramsden SL, Keib N, Schwarz G, Harvey RJ, Hirata H (2011) Duplicated gephyrin genes showing distinct tissue distribution and alternative splicing patterns mediate molybdenum cofactor biosynthesis, gly- cine receptor clustering, and escape behavior in zebrafish. J Biol Chem 286:806-817.

Pfeiffer F, Graham D, Betz H (1982) Purification by affinity chromatography of the glycine receptor of rat spinal cord. J Biol Chem 257:9389-9393.

Prior P, Schmitt B, Grenningloh G, Pribilla I, Multhaup G, Beyreuther K, Maulet Y, Werner P, Langosch D, Kirsch J (1992) Primary structure and alternative splice variants of gephyrin, a putative glycine receptor-tubulin linker protein. Neuron 8:1161-1170.

Pujol-Martí J, Zecca A, Baudoin JP, Faucherre A, Asakawa K, Kawakami K, López-Schier H (2012) Neuronal birth order identifies a dimorphic sensorineural map. J Neurosci 32:2976-2987.

Ramaswami M (2014) Network plasticity in adaptive filtering and behavioral habituation. Neuron 82:1216-1229.

Suwa H, Saint-Amant L, Triller A, Drapeau P, Legendre P (2001) Highaffinity zinc potentiation of inhibitory postsynaptic glycinergic currents in the zebrafish hindbrain. J Neurophysiol 85:912-925.

Swerdlow NR, Geyer MA, Braff DL (2001) Neural circuit regulation of prepulse inhibition of startle in the rat: current knowledge and future challenges. Psychopharmacology 156:194-215.

Tabor KM, Smith TS, Brown M, Bergeron SA, Briggman KL, Burgess HA (2018) Presynaptic inhibition selectively gates auditory transmission to the brainstem startle circuit. Curr Biol 28:2527-2535.e8.

Takahashi H, wase M, Ishii R, Ohi K, Fukumoto M, Azechi M, Ikezawa K, Kurimoto R, Canuet L, Nakahachi T, Iike N, Tagami S, Morihara T, Okochi M, Tanaka T, Kazui H, Yoshida T, Tanimukai H, Yasuda Y, Kudo $\mathrm{T}$ et al. (2008) Impaired prepulse inhibition and habituation of acoustic startle response in Japanese patients with schizophrenia. Neurosci Res 62:187-194

Thompson RF, Spencer WA (1966) Habituation: a model phenomenon for the study of neuronal substrates of behavior. Psychol Rev 73:16-43.

Tyagarajan SK, Fritschy JM (2014) Gephyrin: a master regulator of neuronal function? Nat Rev Neurosci 15:141-156.

Williams LE, Blackford JU, Luksik A, Gauthier I, Heckers S (2013) Reduced habituation in patients with schizophrenia. Schizophr Res 151:124-132.

Wolman MA, Jain RA, Marsden KC, Bell H, Skinner J, Hayer KE, Hogenesch JB, Granato M (2015) A genome-wide screen identifies PAPP-AAmediated IGFR signaling as a novel regulator of habituation learning. Neuron 85:1200-1211.

Wuchter J, Beuter S, Treindl F, Herrmann T, Zeck G, Templin MF, Volkmer H (2012) A comprehensive small interfering RNA screen identifies signaling pathways required for gephyrin clustering. J Neurosci 32:1482114834 .

Yamanaka I, Miki M, Asakawa K, Kawakami K, Oda Y, Hirata H (2013) Glycinergic transmission and postsynaptic activation of CaMKII are required for glycine receptor clustering in vivo. Genes Cells 18:211-224. 